\title{
EEN NEDERLANDSCH GETUIGE OMTRENT DE PLAATS, WAAR COLUMBUS BEGRAVEN LIGT \\ DOOR
}

PROF. J. C. VAN EERDE.

Eenigen tijd geleden werden mij ter hand gesteld enkele stukjes hout, die afkomstig zouden zijn van het kruis, dat bij het graf van Columbus te Santo Domingo moet hebben gestaan.

De schenker, de Heer J. U. Harken, deelde daarbij omtrent de herkomst van deze donkere stukjes hout zulke belangrijke bijzonderheden mede, dat het gewenscht voorkwam van deze bijzonderheden aanteekening te houden en deze voor publicatie te bestemmen, omdat daaruit van de avonturen van een Nederlandschen zeeman blijkt en vooral, wijl zij betrekking hebben op een vraagstuk, dat nog immer velen bezig houdt, nl. de vraag omtrent de juiste plaats, waar Columbus begraven ligt.

Een overzicht van dat vraagstuk is te vinden in het Vijfde jaarlijksch verslag van het Geschied-, taal-, landen volkenkundig genootschap te Willemstad, Amsterdam $1901 \mathrm{blz} .16$ e. v. in een opstel van rector Victor Zwijsen, die van meening is, dat Santo Domingo het gebeente van Columbus nog altijd bezit. Daar tegenover staat de overtuiging van D. Antonio Lopez Prieto, verdedigd in zijn boek Los restos de Colon, Madrid 1879, volgens wien de overblijfselen van Columbus in 1795 naar Cuba zijn overgebracht en dus thans in Spaansche aarde zouden rusten. Het getuigenis van een Nederlander, die in 1877 te Santo Domingo verbleef, toen men daar de ware overblijfselen van Columbus meende te ontdekken, moge dus worden geboekstaafd. 


\section{EEN NEDERL. GETUIGE OMTRENT DE PLAATS}

De Heer Johan Ulrich Harken is thans directeur van de Surinaamsche Bosch-exploitatie maatschappij en was vroeger gezagvoerder van de aan zijne familie toebehoorende brik Havana Packet, een schip van 192 ton, in 1859 te Medemblik gebouwd en toen ter tijd genaamd de Drie Vrienden. Op 22-jarigen leeftijd kwam Harken met zijn schip te St. Thomas, vanwaar hij voor de firma Fedderson Willink en Co. in ballast zou varen naar Monte Christi en Manzanillo (op de Noordkust van Santo Domingo) om daar hout aan boord te nemen voor een haven in Europa, omtrent welke hij Falmouth moest aanloopen voor orders.

Op 15 Augustus 1877 vertrok hij van St. Thomas om drie dagen later te Monte Christi aan te komen, en op 19 Augustus te Manzanillo, zooals zijn „coast permit” hem vergunde.

Te Manzanillo werd mahonie- en ander hout geladen en de Havana Packet vertrok van daar op 12 September 1877 om op den 16den daaropvolgende te Monte Christi terug te keeren, waar de lading zou worden aangevuld en de reis naar Europa zou worden ondernomen.

Gedurende de kustreis van 12-16 September bevond zich, - volgens de mededeelingen van den Heer Harkenaan boord van de Havana Packet een passagieres, die met een door den commandant van het Dominicaansche oorlogsscheepje Carlota afgegeven pas reisde. Te Monte Christi verliet die vrouw het schip en toen de matrozen, die haar later van wal zouden halen om haar in de gelegenheid te stellen haar bagage in ontvangst te nemen, landden, werden zij gevangen genomen evenals de gezagvoerder zelf, toen hij naar zijne mannen ging omzien.

Zij werden beschuldigd van het vervoer van ammunitie ten behoeve van opstandelingen tegen de Dominicaansche regeering; op het schip werd beslag gelegd, de gezagvoerder en zijn stuurman $\mathrm{H}$. K. Mulder werden gevangen gezet, eerst te Porto Plata, later op 6 October 1877 te Santo Domingo.

Zoo was de bekende zaak van de Havana Packet geboren, die in herinnering moge worden gebracht door de 
overneming van een bericht uit de Curaçaosche Courant van 1878 no. 25, dat het volgende overzicht geeft.

\section{DE „HAVANA-PACKET”}

„Sedert October van verleden jaar werd door de autoriteiten van de Republic S. Domingo, het in Nederland tehuis behoorende Brikschip „Havana-Packet”, kapitein J. U. Harken in beslag genomen.

De aanleiding tot deze daad bestond daarin, dat naar beweerd werd de kapitein zijn onderhebbend vaartuig zou hebben verleend tot het vervoeren van oorlogsmateriaal, aan de (toen) opstande lingen toebehoorende, van de eene haven der Republic naar de andere.

In eerste aanleg werd het vaartuig door de regtbank verbeurd verklaard en de kapitein in de kosten van het geding veroordeeld, en wel bij vonnis van den 19den Februari dezes jaars. Van dat vonnis kwam de kapitein in appel bij het „Hooge Geregtshof” der Republiek, dat op den 15den Mei jl. het in het eersten aanleg gewezen vonnis bevestigde met de enkele wijziging, dat de kapitein ontheven werd van de veroordeeling in de kosten welke kosten door den Viscus voldaan zullen worden uit den opbrengst van het vaartuig. De „Gacete de Santo Domingo”, het officieel blad van het dominicaansch Gouvernement bevat in het nummer van den 21sten Mei, het arrest door het hooge gerechtshof den 15den gewezen. Moeijelijk, zoo niet onmogelijk is het uit een enkele lezing van dat stuk, zonder op de hoogte te zijn van wat door de getuige verklaard is (hetgeen het arrest niet vermeld) zich een denkbeeld te kunnen vormen of het arrest, al dan niet in strijd met de regtvaardigheid is, maar wel mag het opmerkelijk heeten dat een vaartuig hetwelk door de vorige regering vervolgd werd omdat het ten gerieve van de opstandelingen wapenen enz. vervoerde, onder de Regering van die vroegere opstandelingen veroordeeld en verbeurd verklaard wordt.

De Heer José M. Leyba, Ned. consul te S. Domingo heeft zich denzelfden dag van de uitspraak van het arrest tot den minister van Buitenlandsche zaken der dominicaansche Republiek gewend, protesteerende tegen de verbeurtverklaring en verdere onwettige handelingen. Met kracht en nadruk handhaaft de Heer Consul in dat stuk de belangen die hem zijn toevertrouwd, met waardigheid wordt de Nederlandsche Regering door hem ten deze vertegenwoordigd. Wij kunnen niet nalaten onze lezers eene ver- 


\section{EEN NEDERL. GETUIGE OMTRENT DE PLAATS,}

taling van dat protest mede te deelen, dat almede in gezegd nummer van de Gaceta van $S^{\text {to }}$.-Domingo voorkomt:

Consulaat der Nederlanden te $\mathrm{S}^{\text {to }}$.-Domingo. No. 139.

$\mathrm{S}^{\text {to }}$. Domingo, 15 Mei 1878.

„Mijnheer de Minister. De Ondergeteekende Consul van Z. M. den Koning der Nederlanden, heeft de eer zich tot Uwe Excell. te wenden, te kennen gevende: dat hij ter voldoening, sedert de maand October van het afgeloopen jaar de loop volgt, die aan den zaak van den Nederlandschen brik „Havana-Packet” gegeven werd, welke zaak aan het oordeel der Regtbanken onderworpen werd ingevolge de wet van den 19den Mei 1876, en zulks wegens het beweerde feit, dat het schip oorlogscontrabande in de wateren van Manzanilla zou bedreven hebben, toen het op een wettige wijze van Monte Christy naar die plaats uitgeklaard was, nadat het de twee visitatiën ondergaan en zijn lading voor Europa ingenomen had, blijkende het, dat bij beide visitatiën het vaartuig op ballast was. Gedurende al dien tijd heb ik er mij toe bepaald om er bij dit en het vorig Gouvernement op aan te dringen, dat deze zaak tot een spoedige beëindiging gebracht zou worden, mij beroepende op de groote nadeelen, die het vaartuig, de kapitein en schepelingen, de inladers en overige belanghebbenden ondervonden; ik voedde de hoop, dat niettegenstaande veroordeeling in eersten aanleg het hooge Geregtshof der Republiek, beter ingeligt omtrent de verschillende punten waarop de aanklacht steunde, en vrij van alle pressie, een arrest zou wijzen gelijk de billijkheid en de groote belangen aan zijn regtvaardig oordeel onderworpen, medebrachten, waardoor de regeling eener zaak vergemakkelijkt ware, die wellicht onaangenaam voor de Republiek zal zijn, misschien nog onaangenamer voor mij, die niet met onverschilligheid kan aanzien, dat de dwaling van enkelen aan het geheele land verwikkelingen berokkenen, die ik zoo gaarne had willen voorkomen. Maar ongelukkig ben ik in mijn verwachtingen teleurgesteld en heb ik vernomen, dat het Hooge Geregtshof, verwerpende hetgeen door den kapitein van den Nederl. brik ter zijner verdediging is aangewend tegen het vonnis van den eersten regter, een veroordeelend arrest heeft gewezen waarbij dat vonnis bevestigd, en het vaartuig verbeurd verklaard wordt, doch bevolen dat de lading worde afgegeven. Ofschoon het arrest van het Hooge Geregtshof tot nu toe niet beteekend is, om welke rede het niet als bijlage bij deze gevoegd is maar daar de openbare uitspraak van het zelve, het onder bereik van het public 
brengt, zoo acht ik het mijn plicht als vertegenwoordiger van de Nederlandsche belangen mij tot UE. te wenden in naam van $Z$. M. den koning der Nederlanden en uit kracht der door mij van mijn Gouvernement ontvangen bevelen te protesteeren, gelijk ik hierbij een en meermalen op de meest plechtige wijze protesteer:

$1^{\circ}$. Tegen de bepalingen van de wet van den 19den Mei 1876, die, gelijk het door Engeland op den 29en Augustus van het zelfde jaar is uiteengezet en waartegen het geprotesteerd heeft, inbreuk maken op het volkenregt, waaraan alle natiën onderworpen zijn. maar vooral die welke tractaten gesloten hebben, welker behoorlijke nakoming op de goede trouw der Natiën steunt;

$2^{\circ}$. Tegen het Gouvernement der dominicaansche Republiek, dat de buitensporigheden en gewelddadigheden toegestaan heeft waarvan Kapitein Harken en zijne schepelingen van de zijde der autoriteiten van Monte Christy de slachtoffers waren, en voor de beleedigingen, de vlag, die hen dekte aangedaan.

$3^{\circ}$. Tegen het Hooge Geregtshof wegens de verantwoordelijkheid die het moge hebben ter zake van de bevestiging van een vonnis, dat klaarblijkelijk in strijd met het volkenregt is en nog meer met de meest gewone practijken.

$4^{\circ}$. Tegen alle autoriteiten die in de zaak zijn tusschenbeide getreden, tegen alle dewelken ter behoorlijke tijde voldoening geëischt worden zal.

$\mathrm{Om}$ al deze redenen en niettegenstaande het grootste leedwezen van mijne zijde verklaar ik aan UE. dat ik namens den kapitein formeel abandonnement van het schip doe, allen wien het moge aangaan verantwoordelijk stellende voor de schade, verliezen en nadeelen die ik mij voorbehoud ter behoorlijker tijd en plaatse te vragen, zonder te prejudiceeren op die welke mede verzocht kunnen worden voor de schaden, verliezen en nadeelen, die de lading mocht blijken geleden te hebben en zoomede alle andere voorwerpen, die zich aan boord van gemeld vaartuig bevonden en uit hetzelve genomen mogten zijn of beschadiging ondervonden hebben.

Met gevoelens van hoogachting enz.

$$
\text { José M. Leyba, consul." }
$$

Het is onnoodig de zaak van de Havana Packet hier nog eens in den breede in herinnering te brengen; genoeg zij het mede te deelen, dat deze zaak het onderwerp van arbitrage heeft uitgemaakt en dat op 26 Maart 1881 door de Nederlandsche en de Dominicaansche regeeringen tot 


\section{EEN NEDERL. GETUIGE OMTRENT DE PLAATS,}

arbiter werd benoemd de president van Frankrijk Jules Grévy, die voorgelicht door eene commissie van onderzoek, op grond van de stukken uitspraak deed bij sententie van 16 Maart 1883, waaraan het volgende is ontleend.

„Attendu que des termes exprès du compromis il résulte que l'arbitre a d'abord à rechercher, si les faits imputés au capitaine Harken qui ont donné lieu à diverses sentences des tribunaux dominicains sont établis par les pièces de la procédure;

attendu qu'aucune constatation matérielle n'a été relevée à la charge du capitaine Harken, que le fait qui a motivé son arrestation et la confiscation du navire Havana-Packet ne résulte que des dépositions de trois ou quatre témoins;

attendu que ces dépositions qui sont contredites par d'autres, qui contiennent des détails invraisemblables n'ont pas été faites en présence du capitaine Harken qui n'a jamais été confronté avec leurs auteurs, alors que rien n'était plus facile que d'opérer cette confrontation;

qu'il y a là un vice essentiel de procédure qui ôte toute valeur probante à l'enquête;

attendu, en conséquence que le fait reproché au capitaine Harken n'est nullement prouvé et que les mesures rigoureuses prises par les autorités dominicaines contre lui, contre son second et contre le navire ne sont pas justifiées;

qu'il n'y a pas lieu, dès lors d'examiner si le fait allégué tombait sous le coup de la loi dominicaine du 19 Mai 1876 ni si cette loi est ou non conforme aux principes du droit international; attendu que le compromis charge l'arbitre dans le cas où le Gouvernement dominicain serait déclaré responsable de fixer l'indemnité qui doit être payée;

attendu qu'en tenant compte de la valeur du navire confisqué, des dépenses diverses nécessitées par le procès de l'emprisonnement et des mauvaises traitements subis par le capitaine et son second, du séjour prolongé que le capitaine a dû faire à $\mathrm{S}^{t}$.Domingue et du temps qui s'est écoulé depuis que le dommage a été causé jusqu'à ce jour, il convient de fixer à cent-quarante mille francs le chiffre de l'indemnité due par le Gouvernement de $\mathrm{S}^{\mathrm{t}}$.-Domingue au Gouvernement des Pays-Bas;

Par ces motifs,

jugeant que le Gouvernement Dominicain doit réparation au Gouvernement des Pays-Bas pour les mesures prises contre le capitaine Harken et le navire Havana Packet. 
Fixons à cent quarante mille francs l'indemnité duê de ce chef par le Gouvernement Dominicain, indemnité qui devra être payé à Paris en monnaie ayant cours en France."

Door de betaling van eene schadevergoeding wegens den aanslag op het leven van den kapitein en de mishandeling hem en den stuurman aangedaan, zoomede wegens de onwettige en willekeurige gevangenhouding van beiden, kwam aan deze zaak een einde. Al kostte het nog heel wat moeite om de uitbetaling van het vastgestelde bedrag te verkrijgen, het avontuur van kapitein Harken eindigde hiermede en wij zullen nu verder hooren, hoe het hem gedurende zijn verblijf te Santo Domingo verging.

Bijna een jaar lang bleef kapitein Harken te Santo Domingo en al spoedig na zijne gevangenneming werd hem toegestaan zich in de stad te bewegen. Zoo had hij de gelegenheid een persoonlijk aandeel te hebben in de vondst van de laatste overblijfselen van Columbus, die men daar toen meende ontdekt te hebben. Omtrent een en ander heeft hij een verhaal opgesteld, dat hier in zijn geheel volgt.

\section{VERHAAL VAN KAPITEIN HARKEN.}

„In September 1877 werd ik als staatsgevangene van de Dominicaansche Regeering met het Amerikaansche Stoomschip „Tybee” overgebracht van Monto-Christo via Porte Plate Samana naar de hoofdstad Santo Domingo, alwaar ik ongeveer 10 October van dat jaar arriveerde.

Gedurende een tiental dagen werd ik daar gevangen gehouden in het Fort Torreon del Homenasa dat aan den ingang staat van de rivier Ozama.

Naar men mij mededeelde, was het vertrek (beter gezegd „hol" zonder uitzicht, waarvan wanden en vloeren slechts uit steen bestonden) waarin ik werd opgesloten, hetzelfde waarin Columbus vóór zijn inscheping naar Spanje gevangen werd gehouden. Dit vertrek - herinner ik mij goed, - heet „Casa de panuela”. Misschien "gaf het feit, dat men kort te voren de ware overblijfselen van Columbus in de groote kathedraal had ontdekt, wel aanleiding tot die vriendelijke mededeeling. 
$\mathrm{Na}$ genoemde 10 dagen werd ik in vrijheid gesteld z.g. onder garantie van het Ned. Consulaat en ik mocht mij vrij in de stad bewegen.

De tijd waarop ik mij toen te $\mathrm{S}^{\text {to }}$. Domingo bevond-ik wees er hierboven reeds op - viel juist samen met de restauratie van de groote kathedraal, waarmede ongeveer in Augustus begonnen was. Ongeveer een maand later werden daarin de ware overblijfselen van Christopher Columbus gevonden.

Mijn verblijf te $\mathrm{S}^{\text {to }}$. Domingo heeft ongeveer negen maanden geduurd. De procesvoering tegen het Dominicaansche Gouvernement vorderde dit.

Intusschen heb ik bijna alles meegemaakt wat op deze ontdekking betrekking had, zooals een nader onderzoek van bedoelde overblijfselen, en de daarmede in verband staande processie etc.

Mijn doel is dan ook, in 't kort mede te deelen wat ik mij omtrent die vondst der laatste overblijfselen van Christoph Columbus herinner gezien te hebben.

In September 1877, toen men aan den binnenkant van de kathedraal een steiger langs de muren van het hoofdkoor had geplaatst, zag men dat een der palen wegzakte en toen bleek bij onderzoek, dat zich daaronder een grafruimte bevond.

In die grafruimte stond een looden kistje, dat als opschrift droeg „El Armirante Don Luis Colon”.

Deze vondst wekte bij den architect Kanunnik Billini de gedachte op, dat er misschien onder het hoofdkoor nog andere graven van beteekenis lagen. Hij stelde dan ook een verder onderzoek in en ontdekte, nadat de ledige grafruimte waaruit de Spanjaarden naar hunne meening de ware overblijfselen van Christoph Columbus genomen hadden, was gevonden aan de linkerzijde van het hoofdkoor een graf, waarin zich ook een looden kistje bevond.

Bij nader onderzoek in het bijzijn van den Bisschop de Orope en andere autoriteiten werd het kistje voor den dag gehaald en bleek dit het volgende opschrift te dragen: D. de la A. Pr. Al. (ontdekker van Amerika Ie Admiraal). Tot zoover hetgeen men mij vertelde. 
Het moet ongeveer half December 1877 geweest zijn, dat er uit Havana een of meer geschiedkundigen te $\mathrm{S}^{\text {to }}$. Domingo aankwamen om te onderzoeken in hoeverre het verhaal omtrent deze vondst waarheid bevatte, daar toch in 1795, toen de Spanjaarden dit gedeelte van het eiland $\mathrm{S}^{\text {to }}$. Domingo aan Frankrijk moesten afstaan, de laatste overblijfselen van Christoph Columbus naar Havana, de hoofdstad van Cuba, waren overgebracht.

$\mathrm{Bij}$ deze gelegenheid werd het kistje, dat sedert de restauratie van de kathedraal naar een andere kerk „Regine Angelorum” was overgebracht en onder toezicht der geestelijkheid bijgezet, weer voor den dag gehaald.

Alle autoriteiten, hooge burgers en consuls waren tegenwoordig en daar ik onder de geestelijken mijne kennissen had en onze consul de heer J. M. Leyba ook geen bezwaar maakte, was ik zoo vrij mij bij de genoodigden aan te sluiten. Ik stond wel niet vooraan maar toch dichtbij genoeg om de letters op de buitenkant en binnenkant van het deksel te onderscheiden.

Het kistje, dat kort na de ontdekking voorzien werd met de zegels van de autoriteiten en consuls werd ontzegeld, geopend en van binnen en buiten nauwkeurig bezichtigd.

Behalve eenige beenderen, bevonden zich ook nog een kogeltje en een zilveren plaatje met inscriptie in het kistje.

$\mathrm{Na}$ de bezichtiging werd het opnieuw verzegeld, in een houten kist geplaatst, en in de kerk opgeborgen.

Kort daarop vond er in verband met deze vondst der ware overblijfselen, naar ik meen reeds de $2 \mathrm{e}$ Processie plaats.

Zooals reeds boven gezegd, had ik kennis gemaakt met enkele der geestelijken waardoor ik tijdens de restauratie nogal eens in de kathedraal kwam. Alles lag daar overhoop, de geheele vloer was opgebroken met het doel een nieuwe marmeren vloer te leggen.

Onder meer stond er ook een vrij groot houten kruis tegen den muur, dat er, niettegenstaande het nu en dan wel eens met groene verf scheen aangestreken te zijn, 
554 EEN NEDERL. GETUIGE OMTRENT DE PLAATS,

toch zeer oud en-lomp uitzag. Op mijn vraag deelde een der geestelijken mij mede, dat dit kruis op het graf van Columbus had gestaan. Onder gewone omstandigheden zou ik zonder meer verder zijn gegaan, maar bij het gebeuren tijdens deze belangrijke vondst, voelde ik er meer interesse voor en verzocht aan den mij vergezellenden geestelijke dan ook, of ik niet een klein stukje als herinnering aan de groote gebeurtenis er mocht afsnijden. Dit werd mij bereidwillig toegestaan en ik was dan ook tot heden nog in 't bezit van dat stukje hout, 't welk ik thans aan prof. van Eerde heb afgestaan.

Professor van Eerde, aan wien ik dezer dagen eenige voorvallen uit mijn wedervaren gedurende mijn verblijf te $\mathrm{S}^{\text {to }}$. Domingo 1877-1878 mededeelde, gaf mij een werkje ter inzage „Los restos de Colon”, Informe de la Real Academia de la Historia" handelende over de zoogenaamde vondst van de ware overblijfselen van Chr. Columbus in de kathedraal van $\mathrm{S}^{\text {to }}$. Domingo, in 1879 uitgegeven te Madrid.

Dit boekje blijkt het resultaat te zijn van het hierboven bedoelde 2e onderzoek door D. Antonio Lopez Prieto, die evenals alle Spanjaarden vurig bestrijdt, dat deze vondst de ware overblijfselen van Columbus zou bevatten. Volgens hem wijzen de bestaande documenten duidelijk uit, dat die in 1795 naar Cuba werden overgebracht.

Op alle mogelijke manieren wordt daarin getracht te bewijzen, dat de vondst in 1877 niet de ware overblijfselen van Columbus zijn.

Onder veel meer wordt daarin aangehaald, dat de inscripties op den buitenkant van de kist en den binnenkant van het deksel 3 verschillende soort letters toonen, waarvan één soort de vorm draagt van een veel lateren tijd. Maar ook het opschrift op de kist D. de la A. Pr. Al. (Descrubidor de la America primar Almirande) moet van lateren tijd zijn. Het woord America ${ }^{\mathbf{1}}$ ) was toen nog zoo

1) Terra America het land van Americus Vespuccius, die later voor den ontdekker is gehouden. 
goed als onbekend en kwam eerst een eeuw later ook in Spanje in gebruik.

In geen geschrift werd het eiland ooit anders dan Isla Espaniola en het vaste land Las Indias genoemd.

Ook omtrent de ligplaats van het graf is men het niet eens en moet de gevonden urn volgens de Spanjaarden dan ook zijn van D. Christoph Columbus, zoon van den Admiraal D. Diego, broer van den Admiraal D. Luis, en neef van den ontdekker. Aan dezen, militair geweest zijnde, is het vinden van een kogel bij het gebeente ook minder vreemd.

Hoe het ook zij, voor de beweringen der Dominicanen valt veel te zeggen tenminste de Spanjaarden kunnen die m.i. niet voldoende weerleggen.

Ook is mij niet bekend wat dan wel op de kist vermeld stond die de Spanjaarden als inhoudende de ware overblijfselen van Christoph Columbus naar Havana hebben overgebracht.

Er is over de quaestie reeds veel geschreven, doch het resultaat is niet anders dan dat de Spanjaarden zoowel als de Dominicanen volhouden, dat zij in het bezit zijn der ware overblijfselen van Chr. Columbus. De Dominicanen hebben die dan ook in een prachtig Mausoleum in de kathedraal te $\mathrm{S}^{\text {to }}$. Domingo bijgezet.

Wat nu betreft het stukje hout, dat afkomstig moet zijn van het kruis, dat op het graf van Columbus heeft gestaan, valt, zooals men uit verschillende schrijvers, over den bouw van de kathedraal en het tijdstip, waarop de overblijfselen van Columbus uit Spanje naar $\mathrm{S}^{\text {to }}$. Domingo werden overgebracht, ook niet met zekerheid te zeggen of bedoeld kruis op het graf van Columbus gestaan heeft of wel, zooals ook beweerd wordt, geplant werd bij de eerste steenlegging van de kathedraal.

De bouw der kathedraal werd in 1514 begonnen en kwam gereed in 1540. Volgens de Kon. Academie van Wetenschappen te Madrid werd door Keizer Karel V in 1537 het besluit bekrachtigd, waarbij het graf van Columbus zou worden overgebracht naar $\mathrm{S}^{\text {to }}$. Domingo ombij gezet te worden in het hoofdkoor. Dit werd in 1539 nog- 
maals bevestigd en uit geschriften van den toenmaligen bisschop van de kathedraal te $\mathrm{S}^{\text {to }}$. Domingo moet gebleken zijn, dat daaraan in 1540 uitvoering is gegeven. Deze bisschop meende echter, dat een graf in het hoofdkoor alleen aan heiligverklaarden mocht worden toegestaan, waarom hij het daarbuiten een plaats aanwees. Eerst later op bevel van D. Luis. Colon. werd het naar het hoofdkoor overgebracht.

Uit het bovenstaande zou men moeten opmaken, dat bedoeld kruis niet op het graf van Columbus heeft gestaan maar wel bij de eerste steenlegging der kathedraal kan geplant zijn.

Is echter de andere bewering juist, dat de laatste overblijfselen van Columbus reeds in 1530 werden overgebracht, toen de kathedraal nog lang niet gereed was, dan kan de mij gedane mededeeling door een der geestelijken te $\mathrm{S}^{\text {to }}$. Domingo juist zijn."

Wie de geschiedenis van Columbus leest, stuit aan het einde immer weder op de mededeeling, dat hier op aarde voor hem slechts onrust was beschoren en dat na zijn verscheiden voor zijn stoffelijk overschot evenmin rust was weggelegd.

Die mededeeling wordt steeds weer nageschreven of in min of meer gewijzigden vorm overgenomen uit Columbus' levensbeschrijving van Washington Irving (Ned. vertaling van 1829 , IV blz. 59), die nog niet vermoeden kon hoe het nageslacht de plaats van dat stoffelijk overschot wijzigen zou en er ten slotte een twistpunt van zou maken.

Volgens Washington Irving stierf Columbus op Hemelvaartsdag 1506 en werd zijn lijk in het klooster van San Francisco te Valladolid ter aarde besteld, waarna het in 1513 werd overgebracht naar het Carthuizer klooster van Los Cuevas te Sevilla.

In 1530, volgens anderen in 1536 of 1540 werd zijn gebeente met dat van zijn zoon Diego vervoerd naar Santo Domingo (zijn geliefde Hispaniola, waar hij bij testament had begeerd te rusten) en na den afstand van 
de Spaansche bezittingen aan Frankrijk in 1795, groef men de overblijfselen, welke men voor die van Columbus hield weder op en bracht deze op 13 Januari 1796 met groote statie naar de hoofdkerk van Cuba. Doch toen ook de ,parel der Antillen” aan Spanje werd ontnomen (in 1898 ) is het stoffelijk overschot van Columbus weder naar Europa gebracht. Is dit inderdaad zoo? Met andere woorden: heeft men in 1795 werkelijk de overblijfselen van Columbus van Santo Domingo naar Havana gebracht of die van een zijner verwanten?

Hierover bestaat tusschen Spanjaarden en Dominicanen verschil van gevoelen en de mededeelingen van den Heer Harken hebben dus het belang van een getuigenis omtrent de opvattingen, die daaromtrent in 1877 te Santo Domingo bestonden. 